\title{
Anti-centromere Antibody-positive Subjects Presenting with Hypertensive Emergency and Renal Dysfunction in the Absence of Skin Manifestations: A Variant of Systemic Sclerosis or a Novel Entity?
}

\author{
Shintaro Mandai ${ }^{1}$, Yohei Arai ${ }^{1}$, Suguru Hirasawa ${ }^{1}$, Toshiyuki Hirai ${ }^{1}$, Shota Aki $^{1}$, \\ Naoto Inaba ${ }^{1}$, Makoto Aoyagi ${ }^{1}$, Hiroyuki Tanaka ${ }^{1}$, Teiichi Tamura ${ }^{1}$ and Sei Sasaki ${ }^{2}$
}

\begin{abstract}
Two patients with anti-centromere antibody (ACA), hypertensive emergency, and acute renal failure, mimicking scleroderma renal crisis, without Raynaud's phenomenon and typical skin manifestations of systemic sclerosis (SSc), are reported. A review of 26 ACA-positive patients between March 2003 and March 2011 in Yokosuka Kyosai Hospital identified four additional patients with similar manifestations. All patients were Japanese women between 41 and 84 years of age at presentation. Human leukocyte antigen (HLA) genotyping tests revealed the absence of the HLA-DQB1*0501 and DRB1*0101 alleles, which are associated with disease susceptibility to ACA-positive SSc among Japanese. These subjects' manifestations may represent a novel entity.
\end{abstract}

Key words: anti-centromere antibody, HLA, hypertensive emergency, renal dysfunction, systemic sclerosis

(Intern Med 51: 1567-1572, 2012)

(DOI: 10.2169/internalmedicine.51.6924)

\section{Introduction}

Anti-centromere antibody (ACA) was discovered by Moroi et al. (1) in 1980 as a specific antibody for CREST syndrome (calcinosis, Raynaud's phenomenon, esophageal dysmotility, sclerodactyly, and telangiectasia), a variant of systemic sclerosis ( $\mathrm{SSc}$ ). Subsequently, it was found that ACA is less frequently detected in a number of other autoimmune diseases, including rheumatoid arthritis, systemic lupus erythematosus, primary Sjögren's syndrome (pSS), and primary biliary cirrhosis (PBC) (2-4). Although both the mechanism of production and the pathogenic role of ACA in each disease have yet to be elucidated, it is well known that ACA is rarely present in healthy individuals worldwide $(5,6)$. Therefore, it is difficult to determine the significance of ACA when these diseases are unlikely. In this paper, 2 ACA-positive patients with malignant or accelerated hypertension involving acute renal failure, mimicking scleroderma renal crisis (SRC), a rare but life-threatening complication of SSc (7), in the absence of skin manifestations, are reported. Furthermore, the clinical features of similar patients are reviewed to investigate whether these manifestations represent a distinct entity.

\section{Case Reports}

\section{Case 1}

A 60-year-old Japanese woman was admitted with marked hypertension and severe renal dysfunction in April 2010. She had a 10-day history of progressively worsening fatigue, anorexia, nausea, and constipation. Her only significant medical history was hyperlipidemia; she had taken no antihypertensive medications. She had no smoking history and no family history of cerebro-cardiovascular disease. On admission, her body weight was $45 \mathrm{~kg}$, her height was 146 $\mathrm{cm}$, and her blood pressure (BP) was $258 / 122 \mathrm{mmHg}$. On

${ }^{1}$ Department of Nephrology, Yokosuka Kyosai Hospital, Japan and ${ }^{2}$ Department of Nephrology, Graduate School of Medicine, Tokyo Medical and Dental University, Japan

Received for publication November 11, 2011; Accepted for publication March 1, 2012

Correspondence to Dr. Shintaro Mandai, smandai@ hotmail.co.jp 


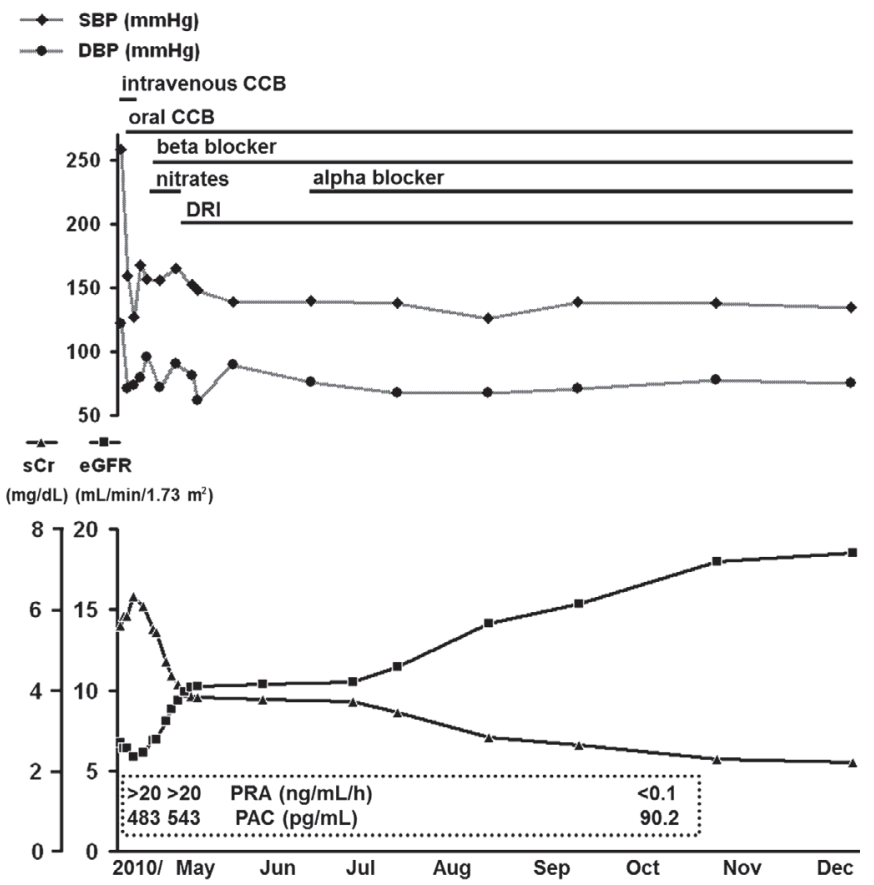

Figure 1. Clinical course of blood pressure, serum creatinine, and estimated glomerular filtration rate in Case 1. CCB: calcium channel blocker, DBP: diastolic blood pressure, DRI: direct renin inhibitor, eGFR: estimated glomerular filtration rate, PAC: plasma aldosterone concentration, PRA: plasma renin activity, SBP: systolic blood pressure, $\mathrm{sCr}$ : serum creatinine

physical examination, her optic fundi showed retinal hemorrhages and exudates without papilledema. Her conjunctivae were pale. A grade III/VI systolic ejection murmur and bilateral crackles were heard on chest examination. No abdominal bruit was heard. Raynaud's phenomenon and skin manifestations were absent. Laboratory results included: hemoglobin, $8.7 \mathrm{~g} / \mathrm{dL}$; white blood cell count, $7,400 / \mu \mathrm{L}$; platelet count $5.8 \times 10^{4} / \mu \mathrm{L}$; urea nitrogen, $83 \mathrm{mg} / \mathrm{dL}$; serum creatinine, $5.59 \mathrm{mg} / \mathrm{dL}$ (estimated glomerular filtration rate (eGFR), $7 \mathrm{~mL} / \mathrm{min} / 1.73 \mathrm{~m}^{2}$ ) (8); sodium, $135 \mathrm{mEq} / \mathrm{L}$; potassium, $3.1 \mathrm{mEq} / \mathrm{L}$; chloride, $90 \mathrm{mEq} / \mathrm{L}$; lactic dehydrogenase (LDH), 1,092 U/L; haptoglobin, $<5 \mathrm{mg} / \mathrm{dL}$; anti-nuclear antibody (ANA), 1:2,560; ACA, 182 (normal: <10); plasma renin activity (PRA), >20 ng/mL/h (normal: 0-2 ng/mL/h); plasma aldosterone concentration (PAC), $483 \mathrm{pg} / \mathrm{mL}$ (normal: 29.9-159 pg/mL); $\mathrm{pH}, 7.474$; partial arterial pressure of oxygen, $82.6 \mathrm{mmHg}$; partial arterial pressure of carbon dioxide, 31.2; bicarbonate, 22.7; and slight hematuria and proteinuria. Anti-neutrophil cytoplasmic antibodies (ANCA), anti-glomerular basement membrane (anti-GBM) antibodies, anti-topoisomerase I (anti-topo I) antibody, anti-double stranded DNA (ant-dsDNA) antibody, anti-Sm antibody, SSA antibody, SSB antibody, and rheumatoid factor were negative. Chest radiography showed cardiomegaly and bilateral pulmonary congestion without pleural effusions. Left ventricular hypertrophy (LVH) was evident on both the electrocardiogram and echocardiogram. An abdominal computed tomography (CT) scan showed no adrenal masses. Ultrasonographic examination showed atrophy of both kidneys and no evidence of renal artery stenosis.

The clinical course and results are shown in Fig. 1. A diagnosis of accelerated hypertension was made on the basis of marked hypertension, progressively worsening renal function, and retinal hemorrhages without papilledema, and the patient was started on intravenous nicardipine. On hospital day 5, intravenous nicardipine was replaced with oral nifedipine $40 \mathrm{mg} /$ day. Subsequently, oral nifedipine was replaced with amlodipine $5 \mathrm{mg} /$ day, isosorbide mononitrate 40 $\mathrm{mg} /$ day, and metoprolol $120 \mathrm{mg} /$ day. The patient's BP was controlled at around $150 / 75 \mathrm{mmHg}$, and her symptoms disappeared. The maximal creatinine was $6.59 \mathrm{mg} / \mathrm{dL}$ (eGFR, $6.0 \mathrm{~mL} / \mathrm{min} / 1.73 \mathrm{~m}^{2}$ ) on day 6 , and renal function started to improve. PRA and PAC were still high $(>20 \mathrm{ng} / \mathrm{mL} / \mathrm{h}$ and $543 \mathrm{pg} / \mathrm{mL}$, respectively); thus, on day 20 , oral isosorbide mononitrate was discontinued, and aliskiren, a direct renin inhibitor, $150 \mathrm{mg} / \mathrm{day}$, was added. There were no adverse events or notable changes except for an increased potassium level from $3.2 \mathrm{mEq} / \mathrm{L}$ to $4.2 \mathrm{mEq} / \mathrm{L}$. The aliskiren dose was increased to $300 \mathrm{mg}$ before discharge. One month later, she showed a further 10/5 mmHg-reduction in BP. Doxazosin 1 $\mathrm{mg} /$ day was added to further decrease her BP, and her BP was controlled at around $135 / 70 \mathrm{mmHg}$. One year after the onset of accelerated hypertension, though her serum creatinine decreased to $2.1 \mathrm{mg} / \mathrm{dL}$ (eGFR, $22.5 \mathrm{~mL} / \mathrm{min} / 1.73$ $\mathrm{m}^{2}$ ), she developed acute myocardial infarction with total occlusion of the right coronary artery. Balloon angioplasty followed by stenting was performed, and she was discharged 2 weeks after admission.

\section{Case 2}

A 41-year-old Japanese woman was admitted to our hospital with severe hypertension and acute renal failure in April 2010. One week previously, she noticed edema of her feet and dyspnea that was worse when lying down. She had no significant medical history, smoking history, or family history of cerebro-cardiovascular diseases. On admission, her body weight was $49.6 \mathrm{~kg}$, her height was $150 \mathrm{~cm}$, and her BP was 226/158 mmHg. On physical examination, her optic fundi showed retinal hemorrhages, exudates, and papilledema. Her conjunctivae were pale. She had edema of her feet. A grade III/VI systolic ejection murmur and bilateral crackles were heard on chest examination. No abdominal bruit was heard. Raynaud's phenomenon and cutaneous manifestations were absent. Laboratory results included: hemoglobin, $8.8 \mathrm{~g} / \mathrm{dL}$; white blood cell count, $11,000 / \mu \mathrm{L}$; platelet count $12.2 \times 10^{4} / \mu \mathrm{L}$; urea nitrogen, $36 \mathrm{mg} / \mathrm{dL}$; serum creatinine, $1.84 \mathrm{mg} / \mathrm{dL}$ (eGFR, $28.4 \mathrm{~mL} / \mathrm{min} / 1.73 \mathrm{~m}^{2}$ ); sodium, $136 \mathrm{mEq} / \mathrm{L}$; potassium, $2.4 \mathrm{mEq} / \mathrm{L}$; chloride, $91 \mathrm{mEq} /$ L; LDH, 611 U/L; ANA, 1:640; ACA, 168; PRA, >20 ng/ $\mathrm{mL} / \mathrm{h}$; PAC, $471 \mathrm{pg} / \mathrm{mL}$; and moderate hematuria and slight proteinuria. ANCA, anti-GBM antibodies, anti-topo I antibody, anti-dsDNA antibody, anti-Sm antibody, SSA antibody, SSB antibody, and rheumatoid factor were negative. 
Chest radiography showed cardiomegaly, bilateral pulmonary congestion, and pleural effusions. LVH was present on both the electrocardiogram and echocardiogram. Abdominal CT showed no adrenal masses. Ultrasonographic examination showed no evidence of renal artery stenosis.

A diagnosis of malignant hypertension was made because of marked hypertension, progressively worsening renal function, and papilledema, and the patient was started on intravenous nitroglycerin. On hospital day 3, intravenous nicardipine was replaced with intravenous nitroglycerin and oral nifedipine $20 \mathrm{mg} / \mathrm{day}$, and intravenous carperitide was used between days 4 and 12. Her symptoms and edema improved gradually. Since her urine output decreased due to rapid BP reduction, stabilization of her BP to around 140/90 $\mathrm{mmHg}$ was performed slowly over a 2 -week period. The maximal creatinine was $2.67 \mathrm{mg} / \mathrm{dL}$ (eGFR, $18.5 \mathrm{~mL} / \mathrm{min} /$ $1.73 \mathrm{~m}^{2}$ ) on day 6 , and renal function started to improve. Subsequently, intravenous nicardipine was replaced with oral bisoprolol $5 \mathrm{mg} /$ day, and the nifedipine dose was increased to $40 \mathrm{mg} /$ day. She was discharged on day 22 . One month later, oral irbesartan $50 \mathrm{mg} /$ day was added, and her BP was controlled at around 130/80 $\mathrm{mmHg}$. One year after the onset of accelerated hypertension, her serum creatinine decreased to $1.68 \mathrm{mg} / \mathrm{dL}$ (eGFR, $31.3 \mathrm{~mL} / \mathrm{min} / 1.73 \mathrm{~m}^{2}$ ).

\section{Discussion}

Malignant hypertension and accelerated hypertension are characterized by marked hypertension and acute end-organ damage, including progressive renal failure and heart failure. The only difference between the two is that papilledema is present with malignant hypertension but not with accelerated hypertension; the prognosis and treatment are the same for these two types of hypertension. Although the prognosis of malignant hypertension has improved with multiple antihypertensive medications, renal involvement is related to higher morbidity and mortality (9). The present patients (Patients 1 and 2 in Table 1) developed malignant hypertension or accelerated hypertension with severe renal dysfunction and laboratory findings suggestive of thrombotic microangiopathy (TMA), a typical histological finding in malignant hypertension (10) or SRC (7), including hemolytic anemia, thrombocytopenia, and elevated LDH. Notably, both patients exhibited high ANA and ACA titers, and their clinical manifestations were similar to those of SRC. However, Raynaud's phenomenon, skin manifestations, and internal organ manifestations, which are typical of SSc, were absent; SSc and SRC were deemed unlikely. Since ACA is rarely detected in healthy individuals $(5,6)$, these patients led us to review the clinical features of ACA-positive patients seen in our hospital.

A review of 26 ACA-positive patients, including 6 patients with CREST syndrome, 3 patients with pSS, and 3 patients with PBC, between March 2003 and March 2011 in Yokosuka Kyosai Hospital, identified 4 additional patients (Patients 3-6 in Table 1) with a past history of renal dys- function and hypertensive emergency, including malignant hypertension, accelerated hypertension, or hypertensive encephalopathy, in the absence of Raynaud's phenomenon and skin manifestations. ACA was identified with positive antibody binding to centromere protein-B (CENP-B), one of the three major CENPs (A, B, and $\mathrm{C}$ ) recognized by most sera with ACA, by enzyme immunosorbent assay (ELISA) using the Mesacup CENP-B test kit (Medical Biological Laboratories Co., Ltd., Nagano, Japan). Relevant clinical data were obtained by chart review and are shown in Table 1. Notably, all patients were women, and their age at presentation with hypertensive emergency varied from 41 to 84 years of age. All patients showed high ACA and ANA titers with discretespeckled patterns using the indirect immunofluorescent technique on Hep-2 cells, and anti-topo I antibody measured by ELIZA using the Mesacup Scl-70 test kit (MBL) was negative. None of the patients were diabetic or had relatives with SSc. Though only patients 3, 5, and 6 in Table 1 had taken antihypertensive medications before presentation, all had $\mathrm{LVH}$, indicating long-term exposure to hypertension. Patient 6 , 55 years of age at presentation, had been a maintenance hemodialysis patient since 51 years of age. Patients 3 and 4 developed accelerated hypertension and progressively worsening renal insufficiency, diagnosed by nephrologists or cardiologists, with laboratory findings suggestive of TMA. Patients 5 and 6 developed hypertensive encephalopathy, which was diagnosed by nephrologists. Hypertension due to volume overload or secondary hypertension such as renal artery stenosis was unlikely in all patients. All patients showed severe renal dysfunction, but primary glomerular diseases such as ANCA-related glomerulonephritis were unlikely because of the absence of specific antibodies at presentation, and slight proteinuria and hematuria at follow-up visits (Table 1). Atrophy of both kidneys in Patient 1 indicated mild to moderate renal dysfunction before hypertensive emergency and acute exacerbation of renal dysfunction, though data on her serum creatinine level before the event was not available. No patient had Raynaud's phenomenon, arthralgia, or cutaneous symptoms typical of SSc such as skin thickening, telangiectasias, or digital ulcers. Patients 1, 4, and 6 were also examined by rheumatologists. Other tests revealed no evidence of pulmonary fibrosis on computed tomography, and there was no evidence of pulmonary hypertension on echocardiogram. Thus, they were not diagnosed as having either diffuse or limited cutaneous SSc, and SRC was unlikely. Although SRC can precede skin manifestations (11), skin manifestations were unchanged in these patients up until the last follow-up visit between 1 and 13 years after presentation. Since previously known diseases that can be accompanied by ACA are unlikely, these subjects' manifestations seem not to represent a variant of SSc, but a distinct entity.

Examinations at follow-up visits were available for 5 of 6 patients (Patients 1, 2, and 4-6 in Table 1), and human leukocyte antigen (HLA) genotyping tests were performed on extracted and purified genomic DNA after informed consent 
Table 1. Characteristics of 6 Patients with Anti-centromere Antibody, Hypertensive Emergency, and Renal Dysfunction

\begin{tabular}{|c|c|c|c|c|c|c|}
\hline & $\begin{array}{l}\text { Patient } 1 \\
\text { (Case 1) }\end{array}$ & $\begin{array}{l}\text { Patient } 2 \\
\text { (Case 2) }\end{array}$ & Patient 3 & Patient 4 & Patient 5 & Patient 6 \\
\hline \multicolumn{7}{|l|}{ Demographic } \\
\hline $\begin{array}{l}\text { Age at presentation } \\
\text { (years) }\end{array}$ & 60 & 41 & 84 & 82 & 57 & 55 \\
\hline Sex & Female & Female & Female & Female & Female & Female \\
\hline Race & Japanese & Japanese & Japanese & Japanese & Japanese & Japanese \\
\hline \multicolumn{7}{|l|}{ Clinical features } \\
\hline $\begin{array}{l}\text { Hypertensive } \\
\text { emergency }\end{array}$ & $\begin{array}{l}\text { Accelerated } \\
\text { hypertension }\end{array}$ & $\begin{array}{r}\text { Malignant } \\
\text { hypertension }\end{array}$ & $\begin{array}{l}\text { Accelerated } \\
\text { hypertension }\end{array}$ & $\begin{array}{l}\text { Accelerated } \\
\text { hypertension }\end{array}$ & $\begin{array}{l}\text { Hypertensive } \\
\text { encephalopathy }\end{array}$ & $\begin{array}{r}\text { Hypertensive } \\
\text { encephalopathy }\end{array}$ \\
\hline $\mathrm{BP}(\mathrm{mmHg})$ & $258 / 122$ & $226 / 158$ & $226 / 105$ & $250 / 115$ & $214 / 122$ & $210 / 90$ \\
\hline Raynaud's phenomenon & No & No & No & No & No & No \\
\hline Skin manifestations & No & No & No & No & No & No \\
\hline ANA & $1: 2,560$ & $1: 640$ & $1: 2,560$ & $1: 640$ & $>1: 2,560$ & $1: 2,560$ \\
\hline ACA (index) & 182 & 168 & 146 & 69.8 & 196 & 182 \\
\hline $\mathrm{sCr}(\mathrm{mg} / \mathrm{dL})$ & 5.59 & 1.84 & 3.86 & 1.39 & 4.30 & ESRD \\
\hline $\mathrm{eGFR}\left(\mathrm{mL} / \mathrm{min} / 1.73 \mathrm{~m}^{2}\right)$ & 7.3 & 28.4 & 9.2 & 28.2 & 9.1 & ESRD \\
\hline Urine protein $(\mathrm{g} / \mathrm{gCr})^{\mathrm{a}}$ & 0.21 & 0.21 & 2.46 & 0.23 & 0.38 & ND \\
\hline Urine occult blood $^{\mathrm{a}}$ & $(-)-(+)$ & $(-)$ & $(-)$ & $(-)$ & $(-)$ & ND \\
\hline $\begin{array}{l}\text { Past history of cerebro- } \\
\text { cardiovascular diseases }\end{array}$ & $\begin{array}{l}\text { Myocardial } \\
\text { infarction }\end{array}$ & No & $\begin{array}{l}\text { Cerebral } \\
\text { infarction }\end{array}$ & $\begin{array}{l}\text { Myocardial } \\
\text { infarction }\end{array}$ & $\begin{array}{r}\text { Cerebral } \\
\text { infarction and } \\
\text { hemorrhage }\end{array}$ & No \\
\hline \multicolumn{7}{|l|}{ HLA genotyping tests } \\
\hline HLA-DQA1 & $\begin{array}{r}030101 \\
0303\end{array}$ & 0104, 0302 & ND & $\begin{array}{r}\text { 0303, } \\
040101\end{array}$ & 0103 & 0104,0303 \\
\hline HLA-DQB1 & $\begin{array}{l}030201 \\
040101\end{array}$ & $\begin{array}{l}030302, \\
050301\end{array}$ & ND & $\begin{array}{r}040101 \\
0402\end{array}$ & 060101 & $\begin{array}{r}040101 \\
050301\end{array}$ \\
\hline HLA-DRB1 & 0405,0802 & $\begin{array}{r}090102 \\
1454\end{array}$ & ND & 0405,0802 & $\begin{array}{c}080302 \\
150201\end{array}$ & 0405,1454 \\
\hline HLA-DPB1 & 0501 & 0501 & ND & 0402 & 0501, 0901 & 0402,0501 \\
\hline
\end{tabular}

ACA: anti-centromere antibody, ANA: anti-nuclear antibodies, BP: blood pressure, eGFR: estimated glomerular filtration rate, ESRD: end-stage renal disease, HLA: human leukocyte antigen, ND: no data, sCr: serum creatinine. ${ }^{a}$ Urine protein and urine occult blood described in the Table were measured after BP was lowered.

was obtained. Previous studies investigated the association of HLA genotyping with disease susceptibility in ACApositive patients. A high frequency of the HLA-DQB1*0501 or DRB1*0101 alleles in Japanese patients with ACApositive SSc was reported $(12,13)$, whereas none of the patients in the present study had them. Furthermore, though HLA-DRB $1 * 0803$ is reportedly associated with the development of PBC in Japanese (14), the gene was present in only 1 patient (Patient 5) who was asymptomatic but had positive anti-mitochondrial antibodies. These findings also suggest that the present patients should be categorized as having a distinct entity different from SSc.

In all subjects, blood pressure was relatively well controlled with intravenous or oral antihypertensive medications, whereas the recovery of renal function was only partial, and the risk of progression to end-stage renal disease (ESRD) seemed very high. Furthermore, 4 of 6 patients had myocardial infarction or stroke before or after the hypertensive emergency event, despite being non-diabetic females with no family history of cerebro-cardiovascular diseases. Patient 3 had a history of cerebral infarction and incomplete paralysis on the right 3 years prior to the hypertensive event, 
and patient 4 had a history of myocardial infarction several years prior to the event. Patient 5 had a history of cerebral infarction and incomplete paralysis on the left 17 years prior to the event and cerebral hemorrhage 2 weeks after the event. This entity appears to be related to a high incidence of ESRD or cerebro-cardiovascular diseases. Permanent control of blood pressure is essential for the prevention of both hypertensive emergency and these complications.

Recent studies have shown that ACA is related with renal dysfunction in limited cutaneous SSc $(\mathrm{lcSSc})(15,16)$. Furthermore, Servettaz et al. (17) revealed that CENP-B was the main target of anti-endothelial cell antibodies (AECA) in lcSSc, which can be present in several autoimmune diseases including systemic lupus erythematosus and SSc, indicating the association of ACA with AECA-mediated endothelial dysfunction. Endothelial dysfunction, especially in renal arterioles by an ACA-related autoimmune mechanism, may be part of the pathology seen in the present entity, because endothelial dysfunction and TMA in renal arterioles play a central role in the pathophysiology of malignant or accelerated hypertension (18). Furthermore, endothelial dysfunction may be associated with a high incidence of cerebrocardiovascular diseases in patients with this entity. The evaluation of these hypotheses requires AECA testing in the present patients, although standardization of AECA testing itself is not fully established.

There are no previous reports of the present entity. Although several previous studies, including Japanese studies, have reviewed ACA-positive subjects, none of them have reported such patients, presumably because the sample sizes were too small, and almost all subjects had Raynaud's phenomenon $(19,20)$. Further possible explanations include the few opportunities to measure ANA or ACA in subjects without any findings suggestive of connective tissue diseases, or the ignorance of the presence of ANA or ACA in such patients. There were 27 patients with hypertensive emergency seen in our hospital between October 2006 and October 2010, and 5 patients (Patients 1-5) had ACA. However, ACA was measured only in 5 of 27 and ANA was in 12. In the present patients, ANA was measured first for various reasons, and subsequently, positive ANA with a discretespeckled pattern by indirect immunofluorescent technique on Hep-2 cells allowed us to measure ACA. The incidence of the present entity may be higher than estimated if ANA or ACA is measured for all subjects with marked hypertension and renal failure, even if they lack skin manifestations. Further studies of such patients are needed to clarify whether their manifestations represent a novel entity.

In conclusion, there may be a novel entity characterized by positive ACA, hypertensive emergency, and renal dysfunction (ACA-related vasculo-renal crisis). This entity appears to be associated with a high incidence of ESRD or cerebro-cardiovascular diseases. Although further studies are needed, this entity may be included in the differential diagnosis of hypertensive emergency or severe renal dysfunction.
The authors state that they have no Conflict of Interest (COI).

\section{Acknowledgement}

The authors are grateful to Dr. Hiromichi Suzuki for critical reading of the manuscript.

\section{References}

1. Moroi Y, Peebles C, Fritzler MJ, Steigerwald J, Tan EM. Autoantibody to centromere (kinetochore) in scleroderma sera. Proc Natl Acad Sci USA 77: 1627-1631, 1980.

2. Nakano M, Ohuchi Y, Hasegawa H, Kuroda T, Ito S, Gejyo F. Clinical significance of anticentromere antibodies in patients with systemic lupus erythematosus. J Rheumatol 27: 1403-1407, 2000.

3. Katano K, Kawano M, Koni I, Sugai S, Muro Y. Clinical and laboratory features of anticentromere antibody positive primary Sjögren's syndrome. J Rheumatol 28: 2238-2244, 2001.

4. Bernstein RM, Callender ME, Neuberger JM, Hughes GR, Williams R. Anticentromere antibody in primary biliary cirrhosis. Ann Rheum Dis 41: 612-614, 1982.

5. Reveille JD, Solomon DH; American College of Rheumatology Ad Hoc Committee of Immunologic Testing Guidelines. Evidencebased guidelines for the use of immunologic tests: anticentromere, Scl-70, and nucleolar antibodies. Arthritis Rheum 49: 399-412, 2003.

6. Sato S, Fujimoto M, Ihn H, Takehara K. Antibodies to centromere and centriole in scleroderma spectrum disorders. Dermatology 189: 23-26, 1994.

7. Penn H, Howie AJ, Kingdon EJ, et al. Scleroderma renal crisis: patient characteristics and long-term outcomes. Q J Med 100: 485494, 2007.

8. Imai E, Horio M, Nitta $\mathrm{K}$, et al. Estimation of glomerular filtration rate by the MDRD study equation modified for Japanese patients with chronic kidney disease. Clin Exp Nephrol 11: 41-50, 2007.

9. Guerin C, Gonthier R, Berthoux FC. Long-term prognosis in malignant or accelerated hypertension. Nephrol Dial Transplant 3: 33-37, 1988.

10. Vaughan CJ, Delanty N. Hypertensive emergencies. Lancet 356: 411-417, 2000.

11. Zwettler U, Andrassy K, Waldherr R, Ritz E. Scleroderma renal crisis as a presenting feature in the absence of skin involvement. Am J Kidney Dis 22: 53-56, 1993.

12. Akimoto S, Abe M, Ishikawa O, Takagi H, Mori M. HLA-DRB1 and DQB1 genes in anticentromere antibody positive patients with SSc and primary biliary cirrhosis. Ann Rheum Dis 60: 639-640, 2001.

13. Kuwana M, Okano Y, Kaburaki J, Inoko H. HLA class II genes associated with anticentromere antibody in Japanese patients with systemic sclerosis (scleroderma). Ann Rheum Dis 54: 983-987, 1995.

14. Nakamura M, Yasunami $M$, Kondo $H$, et al; PBC Study Group in NHOSLJ*. Analysis of HLA-DRB1 polymorphisms in Japanese patients with primary biliary cirrhosis (PBC): The HLA-DRB1 polymorphism determines the relative risk of antinuclear antibodies for disease progression in PBC. Hepatol Res 40: 494-504, 2010 .

15. Gliddon AE, Doré CJ, Dunphy J, Betteridge Z, McHugh NJ, Maddison PJ; QUINS Trial Study Group. Antinuclear antibodies and clinical associations in a british cohort with limited cutaneous systemic sclerosis. J Rheumatol 38: 702-705, 2011.

16. Hesselstrand R, Scheja A, Shen GQ, Wiik A, Akesson A. The association of antinuclear antibodies with organ involvement and survival in systemic sclerosis. Rheumatology 42: 534-540, 2003.

17. Servettaz A, Tamby MC, Guilpain P, et al. Anti-endothelial cell antibodies from patients with limited cutaneous systemic sclerosis 
Intern Med 51: 1567-1572, 2012 DOI: 10.2169/internalmedicine.51.6924

bind to centromeric protein B (CENP-B). Clin Immunol 120: 212219, 2006.

18. van den Born BJ, Koopmans RP, van Montfrans GA. The reninangiotensin system in malignant hypertension revisited: plasma renin activity, microangiopathic hemolysis, and renal failure in malignant hypertension. Am J Hypertens 20: 900-906, 2007.
19. Pakunpanya $K$, Verasertniyom $O$, Vanichapuntu $M$, et al. Incidence and clinical correlation of anticentromere antibody in Thai patients. Clin Rheumatol 25: 325-328, 2006.

20. Soma Y, Takehara K, Ishibashi Y. Clinical distribution of anticentromere antibody in Japanese patients. Dermatologica 178: 16-19, 1989.

(C) 2012 The Japanese Society of Internal Medicine http://www.naika.or.jp/imindex.html 